\title{
Two-stage pancreatic head resection after previous damage control surgery in trauma: two rare case reports
}

\author{
Jorge Paulino ${ }^{1 *} \mathbb{D}$, Emanuel Vigia', Miguel Cunha² and Edgar Amorim²
}

\begin{abstract}
Background: This study describes the successful treatment of two clinical settings of grade $V$ pancreaticoduodenal blunt trauma only possible due to the prompt collaboration of a peripheral trauma hospital and a central hepatobiliary and pancreatic unit.

Case presentation: We reviewed the clinical records of two male patients aged 17 and 47 years old who underwent a two-stage pancreaticoduodenectomy after a previous Damage-Control Surgery (DCS). Both patients were transferred to our Hepatobiliopancreatic Unit 2 days after immediate DCS with haemostasis, debridement, duodenostomy, gastroenterostomy, external drainage and laparostomy. One day after, they both underwent a twostage Whipple's procedure with external cannulation of the main bile duct and the main pancreatic duct with seized calibre silicone drains through the skin. The reconstructive phase was performed two weeks later. The first patient had an uneventful post-operative course and was discharged on post-operative day 8 . The second patient developed a high debt biliary fistula on post-operative day 5 being submitted to a relaparotomy with extensive peritoneal lavage. After conservative measures the fistula underwent a progressive closure in 15 days, and the patient was discharged at post-operative day 50 without any limitations.

Conclusions: Pancreaticoduodenectomy is a life-saving operation in selected grade $V$ pancreaticoduodenal trauma lesions. DCS is a salvage approach, often performed in peripheral hospitals, making an early referral to an hepatobiliopancreatic centre mandatory to achieve survival in these severely injured patients. A two-staged Whipple's operation for severe duodenal / pancreatic trauma can be performed safely and may represent a lifesaving option under these very unusual circumstances.
\end{abstract}

Keywords: Pancreatic trauma, Pancreaticoduodenectomy, Pancreatic injury, Duodenal trauma, Case reports

\section{Background}

Duodenal and pancreatic injuries are very rare compared with those of other abdominal organs. Isolated duodenal injuries have an estimated $4.3 \%$ incidence in all abdominal injuries, and pancreatic trauma occurs in only $3 \%$ $[1,2]$. By its protected retroperitoneal location, an

\footnotetext{
* Correspondence: fusilis@gmail.com

'Centro Hepatobiliopancreático e de Transplantação, Centro Hospitalar Universitário de Lisboa Central, Hospital Curry Cabral, Universidade Nova de Lisboa, Lisboa, Portugal

Full list of author information is available at the end of the article
}

excessive blunt or penetrating trauma is required to be able to injury both the pancreas and the duodenum. This is the main cause to the high rates of associated abdominal injuries under those circumstances [3].

The most common injury is at the neck of the pancreas, by direct compression against the vertebral column, while less commonly, pancreas head or tail injuries may develop due to blows to the flanks [4].

Hemodynamically unstable patients need to have an immediate surgical exploration, often with a DamageControl Surgery (DCS), and the reconstructive 
interventions should be planned at a later stage, when the potentially lethal factors (haemorrhage, shock, peritonitis, acidosis, hypothermia or coagulopathy) are treated efficaciously and the patient is stabilized [5].

However, many complex injuries occur far from differentiated medical centres, and the first approach to these complex patients is made in peripheral hospitals, lacking surgeon and institutional experience, making crucial an early referral collaboration [6]. Under these circumstances pancreaticoduodenectomy is a very uncommon procedure, and a two-stage operation may be considered if the surgeon is dealing with an unstable patient $[7,8]$. Moreover, this approach is usually reserved for the most severe injuries of both the head of the pancreas and the duodenal arch, grade 4 or 5 according with the organ injury scale and the American Association for the Surgery of Trauma $[9,10]$ (Table 1).

Here we present two cases of severe blunt duodenal / pancreatic trauma, using this two-stage approach after a previous DCS. Both patients had been managed previously with haemostatic procedures followed by gastroenterostomy before being referred to our institution for definitive surgery.

\section{Case presentation}

\section{First clinical setting}

A 17-year-old male suffered a severe motorcycle accident with a deep upper abdominal blunt trauma. Soon after the accident he was resuscitated and taken for emergency laparotomy at the nearest Trauma Centre. A massive right-sided retroperitoneal hematoma was detected, with active haemorrhage from a severely disrupted pancreatic head, duodenum and lower biliary tract. An extended Kocher manoeuvre was performed while compressing the hepatoduodenal ligament for haemostasis. At that time a main pancreatic duct disruption was demonstrated, without any evidence of the portal or the superior mesenteric vein involvement. The patient was hypothermic and moderately acidotic, fostering a DCS. After multiple sutures around the avulsion areas, the active bleeding was stopped and a cholecystectomy, complemented with a silicone T-tube drainage of the main bile duct and a gastroenterostomy were performed, as well as a duodenostomy with a Foley catheter. Two large silicone drains were placed and the patient was transferred to Lisbon by plane, with a laparostomy.

The patient was admitted in the Intensive Care Unit (ICU) of Curry Cabral Hospital where supportive care was initiated. Improvement of physiological parameters and hemodynamic stability was achieved in $48 \mathrm{~h}$, despite a progressive biliary drainage from the silicone rubber drains.

A second surgery was then decided, revealing bile staining throughout the entire peritoneal cavity, revealing slight oedema of the bowel loops without contamination. A Whipple's resection was performed, exposing a main bile duct of around $5 \mathrm{~mm}$ diameter and a centred and easily located $3 \mathrm{~mm}$ main pancreatic duct: they were both cannulated with seized calibre silicone drains exiting the abdomen through the skin. Before closing the abdomen both catheters were secured to the surrounded parenchyma with a nylon transfixed suture, and the right upper quadrant was drained with two closed suction systems (Fig. 1).

The post-operative course was uneventful. Fourteen days later the reconstructive operation was performed without any unusual factors, and a classical Whipple operation was completed after removal of the well-placed

Table 1 Organ injury scale of the American Association for the Surgery of Trauma

\begin{tabular}{|c|c|c|}
\hline $\begin{array}{l}\text { Injured structure and AAST } \\
\text { grade }\end{array}$ & Characteristics of injury & $\begin{array}{l}\text { AIS - } 2005 \\
\text { score }\end{array}$ \\
\hline \multicolumn{3}{|l|}{ Pancreas } \\
\hline I & Small hematoma without duct injury; superficial laceration without duct injury & 2 \\
\hline$\|$ & $\begin{array}{l}\text { Large hematoma without duct injury or tissue loss; major laceration without duct injury or tissue } \\
\text { loss }\end{array}$ & 2 \\
\hline III & Distal transection or parenchymal laceration with duct injury & 3 \\
\hline IV & Proximal transection or parenchymal laceration involving ampulla & 4 \\
\hline V & Massive disruption of pancreatic head & 5 \\
\hline \multicolumn{3}{|l|}{ Duodenum } \\
\hline 1 & Single-segment hematoma; partial-thickness laceration without perforation & 2 \\
\hline$\|$ & Multiple-segment hematoma; small (\50\% of circumference) laceration & 2 \\
\hline III & $50-75 \%$ Disruption (laceration) of segment D2 or 50-100\% disruption of segment D1, D3, or D4 & 3 \\
\hline IV & Large (75-100\%) laceration of segment D2; rupture of ampulla or distal CBD & 4 \\
\hline V & Massive duodenopancreatic injury; devascularization of duodenum & 5 \\
\hline
\end{tabular}

Scores were collected from the organ injury scale of the American Association for the Surgery of Trauma [9] and the Abbreviated Injury Scale (AIS 2005) [10] 


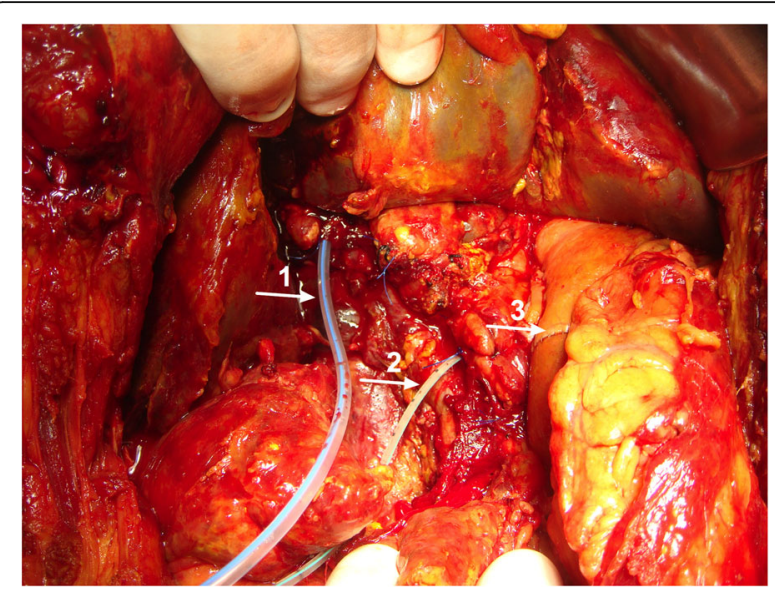

Fig. 1 Resection of the pancreatic head and duodenum. Resection was performed and the silicon endoluminal catheters have been secured in place with nylon sutures and are indicated by arrows: 1 endoluminal catheter in main bile duct; 2 - endoluminal catheter in main pancreatic duct; 3 - gastrojejunostomy

silicone endoluminal catheters. Again, the post-operative course was uneventful and the patient was discharged from the hospital at post-operative day 8 .

\section{Second clinical setting}

This patient was a 47-year-old male paddle-surfer who suffered a severe deep and blunt trauma in the upper abdomen with his paddle-surf board. He was immediately transported to the nearest emergency room (Trauma Centre of Portimão Hospital), where he was submitted to a first medical evaluation. At that time, he was hemodynamically stable but with severe abdominal tenderness and acute abdomen signs. An abdominal CT scan revealed a haemopneumoperitoneum with distinctive evidence of pancreatic contusion in the uncinated process and duodenal rupture. No main pancreatic duct disruption was shown. He was then sent to emergency surgery and a median laparotomy was performed. There was a $300 \mathrm{cc}$ haemoperitoneum with its origin in the duodenum and the head of the pancreas, but as in the first clinical setting, there was no lesion detected in the portal or the superior mesenteric vein. A more than $75 \%$ rupture of the second duodenum was confirmed, with alleged bile duct integrity and a complete main pancreatic duct disruption in the neck (Fig. 2). A DCS was performed, with haemostasis, a duodenostomy with a Foley catheter, a silicone $\mathrm{T}$-tube drainage of the main bile duct (after a normal cholangiography), cholecystectomy and a gastroenterostomy (Fig. 3). Again, two large silicone rubber drains were placed and the patient was transferred by plane to the HPB Unit of Curry Cabral Hospital, with a laparostomy.

The patient was admitted in the ICU of Curry Cabral Hospital, obtaining an improvement of physiological

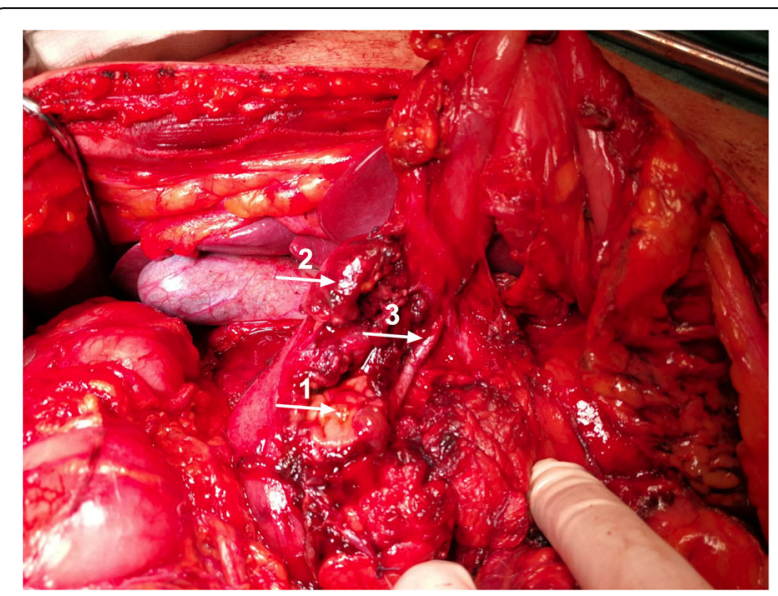

Fig. 2 View after haemostasis, showing a more than 75\% rupture of the second duodenum (arrow 1), massive disruption of pancreatic head (arrow 2) and denudation of the main bile duct (arrow 3)

parameters and achieving hemodynamic stability in $48 \mathrm{~h}$, once again with a progressive drainage rich in amylase from the silicone rubber drains.

As the drainage turned biliary, a second surgery was then decided, confirming bile content throughout all the peritoneal cavity, with considerable oedema of the bowel loops. A Whipple's resection was performed, exposing a main bile duct of around $4 \mathrm{~mm}$ diameter and a centred and easily located $3 \mathrm{~mm}$ main pancreatic duct with a normal consistency parenchyma. The same surgical protocol was used, cannulating both ducts with seized calibre silicone drains exiting the abdomen through the skin (Fig. 4).

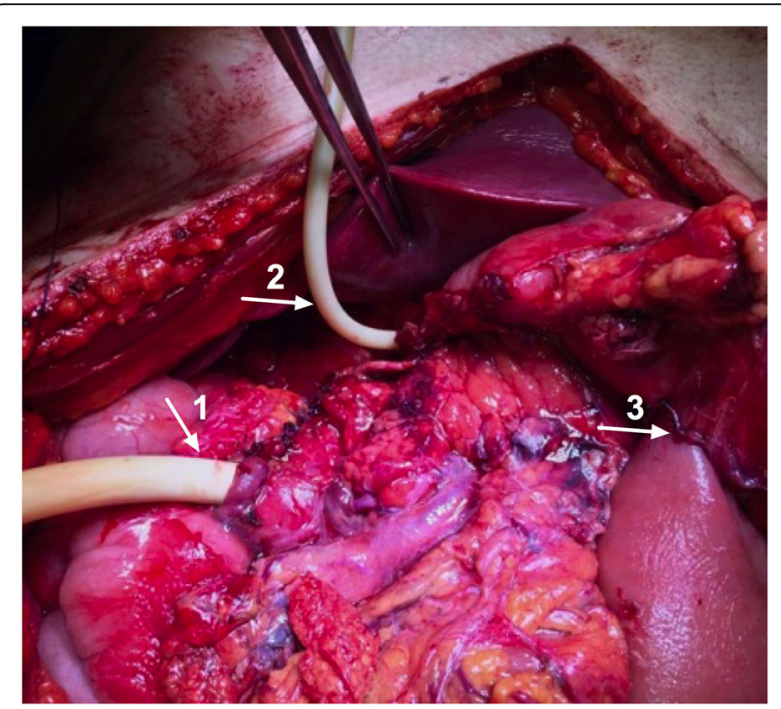

Fig. 3 View after resection of the D1 and part of D2, tube duodenostomy (arrow 1), showing the T tube in the common bile duct (arrow 2) and gastroenterostomy (arrow 3) 


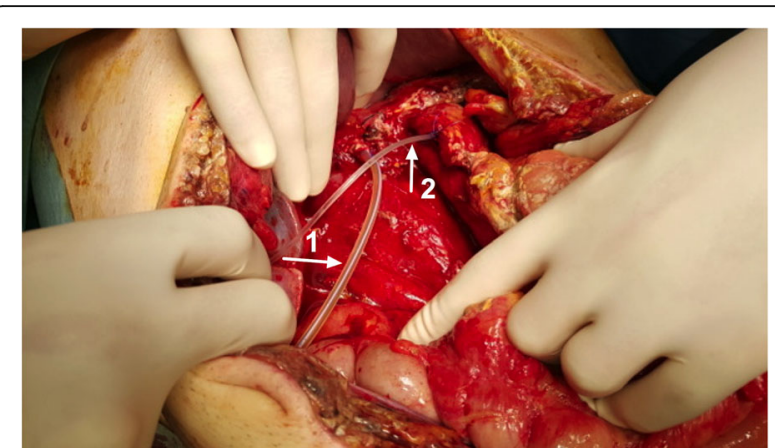

Fig. $4 \mathrm{View}$ after the resection, showing both catheters secured to the surrounded parenchyma with a nylon transfixed suture, indicated by arrows: 1 - endoluminal catheter in main bile duct; 2 endoluminal catheter in main pancreatic duct

Again, both catheters were secured to the surrounded parenchyma with a nylon transfixed suture, and the right upper quadrant was drained with two closed suction drains. The abdomen was then closed.

The post-operative course was uneventful. Sixteen days later, the reconstructive operation was performed just as in the previous case, and a classical Whipple was completed after removal of the well-placed silicone endoluminal catheters.

The post-operative course was uneventful until the 5 th day. At this point, there was progressive abdominal pain and a high debt biliary fistula, both from the drain and the abdominal wall. A relaparotomy was then performed, with extensive peritoneal lavage, confirming an impenetrable and sealed upper abdominal compartment: the suction drains were changed and the laparotomy was closed with separated full-thickness stiches.

After conservative measures and serial image control, the fistula underwent a progressive closure in 15 days, and the patient was discharged from the hospital at post-operative day 50 . He reported returning to his normal lifestyle without any limitations.

\section{Discussion and conclusions}

Whipple's procedure in trauma-related circumstances is a very unusual procedure. This kind of pancreatic resection was reported for the first time in literature for trauma patients in the $60 \mathrm{~s}[11,12]$. This is due to the very low incidence of duodenal and pancreatic injuries compared to other abdominal organs (respectively 4.3 and $2.0 \%$ of all abdominal injuries) [13-15], and to the very high mortality rate ranging from 20 to $100 \%$ [16, 17].

The two cases described were both grade $\mathrm{V}$, making a surgical approach inevitable. Nonoperative management would be inappropriate in these high-grade injuries, as it has been demonstrated in retrospective studies [18, 19]. This is not an absolute truth since non-operative treatment for severe lesions is possible as demonstrated by Wilden in one of the largest retrospective studies [20]. However, in these two cases the presence of both extensive trauma to the head of the pancreas and severe combined pancreaticoduodenal injury justified the operative decision [21]. The clinical and geographic circumstances determined the option of performing DCS as the first approach $[22,23]$. This strategy is indicated with acidosis $(\mathrm{pH}<7.3)$, hypothermia (temperature $<$ $35^{\circ} \mathrm{C}$ ) and coagulopathy (non-mechanical bleeding) [24].

Due to its rarity, the application of DCS techniques in relation to pancreatic and duodenal injuries is hardly ever described in literature, aiming at preventing further haemorrhage or abdominal contamination with bile and pancreatic juices [25]. Packing combined with adequate pancreatic and duodenal drainage, as in the primary approach of these two cases, was the appropriate DCS technique under those circumstances [26]. The need for total pancreatectomy is exceptional during DCS, under these circumstances. However, it might be considered only as a definitive procedure, if the extent of debridment required left no other choice. This difficult decision might be taken only by a center specialized in pancreatic surgery.

Also, attempting a Whipple's resection on a coagulopathic, hypothermic and acidotic patient, is considered very risky, assuming that a higher experience / better outcomes relation is also true in unstable trauma patients [20].

Additionally, the status of the main pancreatic duct as well as the global status of the patient determinate the management of pancreatic injuries. Screening trauma patients for pancreatic injury using CT scan must be cautious since the sensitivity is reported as poor, as in the second clinical case [27]. A careful inspection and a bimanual palpation of the pancreas should be enough to demonstrate a main duct injury, avoiding added risk by other manoeuvres such as intraoperative pancreatography [28].

In most cases described in literature, the second and definite surgery is performed in approximately $48 \mathrm{~h}$, allowing appropriate staff and patient conditions. In the two cases described, however, the second surgery has been precipitated by the aggravation of the abdominal conditions, namely the bile content throughout the whole peritoneal cavity. The high amylase content of the drainage activated the bile leaking from the injured duodenum, and led to a pancreatitis-like reaction and to a considerable oedema of the bowel loops, which, altogether, precluded the immediate reconstruction after pancreaticoduodenectomy. One might argue why deciding to postpone the definitive reconstruction, as it was taking place at an experienced hospital, with an experienced pancreatic team. There is evidence that, 
performing anastomosis despite the unfavourable presented circumstances is as safe as delaying it into a twostage procedure (38.7\% vs $34.2 \%$ mortality) [29]. Nevertheless, assuming such a high late mortality rate, mostly due to multiple organ failure and sepsis [30] discouraged us to do so, particularly after an open abdomen scenario.

The appropriate conditions of both the common hepatic duct and the main pancreatic duct made safe and possible to cannulate both with separate silicon catheters, allowing a total and separated external drainage of bile and pancreatic content. Both drainages were left in place in a good position, allowing local conditions for the final surgical step.

The length of time until the anastomotic surgery (15 days) was decided based on the stabilization of the clinical situation of the patient. Although this could be considered a late timing since it might correspond to a high peritoneal inflammatory reaction after a biliary peritonitis, it has been reported that in abdominal sepsis caused by secondary peritonitis, the acute phase proteins synthesis stimulated by cytokines recover to normal values only after day 12 of the post-operative period [31]. The fact that, in both cases, there were no inaccessible exsanguinant lesions involving both the retropancreatic portal nor the superior mesenteric vein, allowed this 15-day delay between the two stages of pancreatoduodenectomy; under those circumstances, that period would have been considered excessive [32]. Moreover, there is no recommendation in literature concerning the timing of the definitive procedure. On the second patient, we repeated the surgical protocol previously used and based on the excellent outcome of the first clinical setting. The significant morbidity (biliary fistula) reported in the second clinical setting may reflect the inappropriate judgement of the optimal local conditions after a pancreatitislike reaction. There are no recommendations found whatsoever, concerning the optimal approach of pancreatic and duodenal grade $\mathrm{V}$ injuries due to its rarity. Most publications are based on case reports, like ours, making it difficult to interpret the scarce literature available [33].

Pancreatic and duodenal trauma remains a clinical challenge, with a high mortality rate. Grade V injuries are difficult to deal with, as they occur very rarely, lacking high level evidence based recommendations in the literature. DCS definitely changed the references for these severe cases [34], but the mortality remains high, with most deaths occurring before a definitive management [33].

Early diagnosis remains problematic, especially following blunt abdominal trauma. The presence of main pancreatic duct injury is one of the major determinants of both morbidity and treatment decisions.

Trauma Whipple procedure may be inevitable in the sequence of previous DCS, and it should always be decided after early patient referral to an experienced hepatobiliary and pancreatic centre, avoiding inappropriate aggressive or conservative indications.

In conclusion, reconstruction after a pancreaticoduodenectomy for duodenal / pancreatic trauma can be performed safely as a two-staged procedure and may represent a life-saving option under these very unusual circumstances.

\section{Abbreviations \\ CT: Computed tomography; DCS: Damage-Control Surgery; HPB: Hepatopancreatobiliary; ICU: Intensive Care Unit}

\section{Acknowledgements}

Authors thank the trauma teams at Hospital Curry Cabral and Portimão, Portugal, for their cooperative work.

\section{Authors' contributions}

J.P., E.V., M.C. and E.A. performed the clinical work, J.P. and E.V. analyzed the data, J.P., E.V., M.C. and E.A. interpreted and discussed the work, J.P. drafted the work, all authors critically revised and approved the final version.

Funding

No funding.

\section{Availability of data and materials}

The datasets generated and/or analysed during the current study are not publicly available due to protecting individual patient privacy but are available from the corresponding author on reasonable request.

\section{Ethics approval and consent to participate}

This study has been reviewed by the Ethics Committee of the Hospital Curry Cabral, all procedures performed in studies involving human participants were conducted according to the ethical standards of the institutional research committee and with the 1964 Helsinki declaration and its later amendments or comparable ethical standards.

\section{Consent for publication}

Written informed consent for publication of the participant images and clinical details were obtained from each patient. Written informed consent for publication was obtained from a parent of the participant under the age of 18 .

Competing interests

The authors declare that they have no competing interests.

\section{Author details}

${ }^{1}$ Centro Hepatobiliopancreático e de Transplantação, Centro Hospitalar Universitário de Lisboa Central, Hospital Curry Cabral, Universidade Nova de Lisboa, Lisboa, Portugal. ²Department of Surgery, Centro Hospitalar Universitário do Algarve - Unidade de Portimão, Portimão, Portugal.

Received: 28 November 2019 Accepted: 30 April 2020

Published online: 12 May 2020

\section{References}

1. Potoka DA, Gaines BA, Leppaniemi A, Peitzman AB. Management of blunt pancreatic trauma: what's new? Eur J Trauma Emerg Surg. 2015;41(3):23950. https://doi.org/10.1007/s00068-015-0510-3.

2. Kollar D, Molnar FT, Zsoldos P, Benedek-Tóth Z, Olah A. Diagnosis and management of blunt pancreatic trauma. Surg Gastroenterol Oncol. 2018; 23(1):5-15. https://doi.org/10.21614/sgo-23-1-5.

3. Berne CJ, Donovan AJ, Hagen WE. Combined duodenal pancreatc trauma. The role of end-to-side gastrojejunostomy. Arch Surg. 1968:96(5):712-22.

4. Gagne S, O Sullivan-Murphy B, Lo HS, McIntosh L. Pancreaticobiliary trauma: a multimodality imaging update. Semin Ultrasound CT MR. 2018; 39(4):355-62. https://doi.org/10.1053/j.sult.2018.03.004.

5. Krige JEJ, Kotze UK, Setshedi M, Nicol AJ, Navsaria PH. Management of pancreatic injuries during damage control surgery: an observational 
outcomes analysis of 79 patients treated at an academic level 1 trauma Centre. Eur J Trauma Emerg Surg. 2017;43(3):411-20. https://doi.org/10. 1007/s00068-016-0657-6.

6. Akhrass $R$, Yaffe MB, Brandt CP, Reigle M, Fallon WF Jr, Malangoni MA Pancreatic trauma: a ten-year multi-institutional experience. Am Surg. 1997; 63(7):598-604.

7. Koniaris LG, Mandal AK, Genuit T, Cameron JL. Two-stage trauma pancreaticoduodenectomy: delay facilitates anastomotic reconstruction. J Gastrointest Surg. 2000;4(4):366-9.

8. Gupta V, Wig JD, Garg H. Trauma pancreaticoduodenectomy for complex pancreaticoduodenal injury. Delayed reconstruction. JOP. 2008;9(5):618-23.

9. Moore EE, Cogbill TH, Malangoni MA, Jurkovich GJ, Champion HR, Gennarelli TA, et al. Organ injury scaling, Il: pancreas, duodenum, small bowel, colon, and rectum. J Trauma. 1990;30(11):1427-9.

10. Gennarelli TA, Wodzin E, Association for the Advancement of Automotive Medicine. Abbreviated injury scale 2005: update 2008. Barrington: Association for the Advancement of Automative Medicine; 2008.

11. Thal AP, Wilson RF. A pattern of severe blunt trauma to the region of the pancreas. Surg Gynecol Obstet. 1964;119:773-8.

12. Foley WJ, Gaines RD, Fry WJ. Pancreaticoduodenectomy for severe trauma to the head of the pancreas and the associated structures: report of three cases. Ann Surg. 1969;170(5):759-65.

13. Asensio JA, Feliciano DV, Britt LD, Kerstein MD. Management of duodenal injuries. Curr Probl Surg. 1993;30(11):1023-93.

14. Glancy KE. Review of pancreatic trauma. West J Med. 1989;151(1):45-51.

15. Lopez PP, Benjamin R, Cockburn M, Amortegui JD, Schulman Cl, Soffer D, et al. Recent trends in the management of combined pancreatoduodenal injuries. Am Surg. 2005;71(10):847-52.

16. Gentilello LM, Cortes V, Buechter KJ, Gomez GA, Castro M, Zeppa R. Whipple procedure for trauma: is duct ligation a safe alternative to pancreaticojejunostomy? J Trauma. 1991;31(5):661-7 discussion 7-8.

17. Yellin $A E$, Rosoff $L$ Sr. Pancreatoduodenectomy for combined pancreatoduodenal injuries. Arch Surg. 1975;110(10):1177-83.

18. Velmahos GC, Tabbara M, Gross R, Willette P, Hirsch E, Burke P, et al. Blunt pancreatoduodenal injury: a multicenter study of the research consortium of New England centers for trauma (ReCONECT). Arch Surg. 2009;144(5): 413-9; discussion 9-20. https://doi.org/10.1001/archsurg.2009.52.

19. Duchesne JC, Schmieg R, Islam S, Olivier J, McSwain N. Selective nonoperative management of low-grade blunt pancreatic injury: are we there yet? J Trauma. 2008;65(1):49-53. https://doi.org/10.1097/TA. ob013e318176c00d.

20. van der Wilden GM, Yeh D, Hwabejire JO, Klein EN, Fagenholz PJ, King DR, et al. Trauma Whipple: do or don't after severe pancreaticoduodenal injuries? An analysis of the National Trauma Data Bank (NTDB). World J Surg. 2014;38(2):335-40. https://doi.org/10.1007/s00268-013-2257-5.

21. Subramanian A, Dente CJ, Feliciano DV. The management of pancreatic trauma in the modern era. Surg Clin North Am. 2007;87(6):1515-32, x. https://doi.org/10.1016/j.suc.2007.08.007.

22. Timmermans J, Nicol A, Kairinos N, Teijink J, Prins M, Navsaria P. Predicting mortality in damage control surgery for major abdominal trauma. S Afr J Surg. 2010;48(1):6-9.

23. Moore EE, Thomas G. Orr memorial lecture. Staged laparotomy for the hypothermia, acidosis, and coagulopathy syndrome. Am J Surg. 1996;172(5): 405-10.

24. Rotondo MF, Zonies DH. The damage control sequence and underlying logic. Surg Clin North Am. 1997;77(4):761-77.

25. Krige JE, Navsaria PH, Nicol AJ. Damage control laparotomy and delayed pancreatoduodenectomy for complex combined pancreatoduodenal and venous injuries. Eur J Trauma Emerg Surg. 2016;42(2):225-30. https://doi. org/10.1007/s00068-015-0525-9.

26. Seamon MJ, Kim PK, Stawicki SP, Dabrowski GP, Goldberg AJ, Reilly PM, et al. Pancreatic injury in damage control laparotomies: is pancreatic resection safe during the initial laparotomy? Injury. 2009;40(1):61-5. https:// doi.org/10.1016/j.injury.2008.08.010.

27. Schellenberg M, Inaba K, Bardes JM, Cheng V, Matsushima K, Lam L, et al. Detection of traumatic pancreatic duct disruption in the modern era. Am J Surg. 2018;216(2):299-303. https://doi.org/10.1016/j.amjsurg.2018.06.002.

28. Heitsch RC, Knutson CO, Fulton RL, Jones CE. Delineation of critical factors in the treatment of pancreatic trauma. Surgery. 1976;80(4):523-9.

29. de Carvalho M, Cunha AG. Pancreaticodudonectomy in trauma: one or two stages? Injury. 2020. https://doi.org/10.1016/j.injury.2020.01.018.
30. Petrone P, Moral Alvarez S, Gonzalez Perez M, Ceballos Esparragon J, Marini CP. Pancreatic trauma: management and literature review. Cir Esp. 2017. 95(3):123-30. https://doi.org/10.1016/j.ciresp.2016.05.011.

31. Milic L, Grigorov I, Krstic S, Ceranic MS, Jovanovic B, Stevanovic J, et al. Serum level of HMGB1 protein and inflammatory markers in patients with secondary peritonitis: time course and the association with clinical status. J Med Biochem. 2017;36(1):44-53. https://doi.org/10.1515/jomb-2016-0016.

32. Sharma AK. Management of pancreaticoduodenal injuries. Indian J Surg. 2012;74(1):35-9. https://doi.org/10.1007/s12262-011-0386-3.

33. Ho VP, Patel NJ, Bokhari F, Madbak FG, Hambley JE, Yon JR, et al. Management of adult pancreatic injuries: a practice management guideline from the eastern Association for the Surgery of trauma. J Trauma Acute Care Surg. 2017;82(1):185-99. https://doi.org/10.1097/TA.0000000000001300.

34. Nicol AJ, Navsaria PH, Krige JE. Damage control surgery. S Afr J Surg. 2010; 48(1):4-5.

\section{Publisher's Note}

Springer Nature remains neutral with regard to jurisdictional claims in published maps and institutional affiliations.

Ready to submit your research? Choose BMC and benefit from:

- fast, convenient online submission

- thorough peer review by experienced researchers in your field

- rapid publication on acceptance

- support for research data, including large and complex data types

- gold Open Access which fosters wider collaboration and increased citations

- maximum visibility for your research: over $100 \mathrm{M}$ website views per year

At BMC, research is always in progress.

Learn more biomedcentral.com/submissions 